\title{
Extraction behaviors of aqueous PEG impregnated resin system in terms of impregnation stability and recovery via protein impregnated resin interactions on bovine serum albumin
}

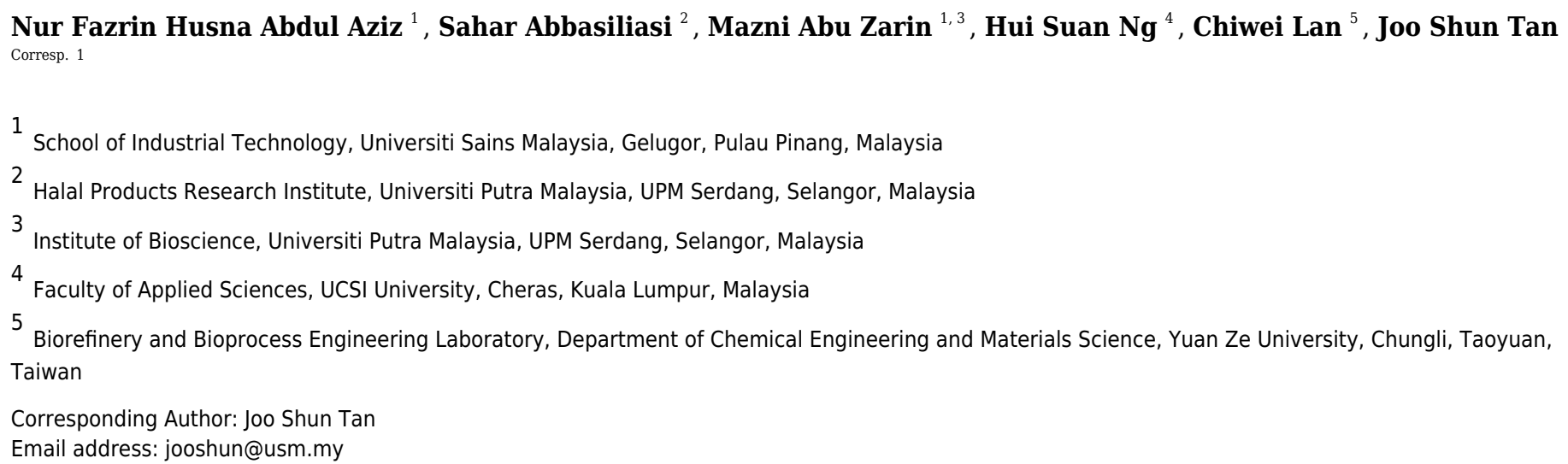

Background: Current advances in biotechnology have been looked at as alternative approaches towards the limited product recovery due to time- and cost-consuming drawbacks on the conventional purification methods. This study aimed to purify bovine serum albumin (BSA) as an exemplary target product using an aqueous impregnated resin system (AIRS). This method implies the concept of hydrophobicity of polymer that impregnated into the resins and driven by electrostatic attractions and hydrophilicity of salt aqueous solution to extract the target product. Methods: The extraction behaviors of impregnation in terms of stability and adsorption kinetics via protein-aqueous polymer impregnated resin were studied. Impregnation stability was determined by the leaching factor of polyethylene glycol (PEG). The major factors such as PEG molecular weight and concentration, $\mathrm{pH}$ of salt aqueous solution, extraction methods (sonication and agitation) and types of adsorbent material and concentration of salt aqueous phase influencing on partitioning of biomolecule were also investigated. Results: For impregnation stability, the leaching factor for Amberlite XAD4 did not exceed 1\%. The scanning electron microscopy (SEM) image analysis of Amberlite XAD4 attributes the structural changes with impregnation of resins. For adsorption kinetics, Freundlich adsorption isotherm with the highest $R^{2}$ value $(0.95)$ gives an indication of favorable adsorption process. Performance of AIRS impregnated with $40 \%$ (w/w) of PEG 2000 was found better than aqueous-two phase system (ATPS) by yielding the highest recovery of BSA (53.72\%). The outcomes of this study propound the scope for application of AIRS in purification of biomolecules. 
1 Extraction behaviors of aqueous PEG impregnated resin system in terms of

6 Joo Shun $\operatorname{Tan}^{1, *}$

$7 \quad{ }^{1}$ School of Industrial Technology, Universiti Sains Malaysia, Gelugor, Pulau Pinang, Malaysia

82 Halal Products Research Institute, Universiti Putra Malaysia, UPM Serdang, Selangor, $9 \quad$ Malaysia

$10{ }^{3}$ Institute of Bioscience, Universiti Putra Malaysia, Serdang, Selangor, Malaysia

$11{ }^{4}$ Faculty of Applied Sciences, UCSI University, UCSI Heights, Cheras, Kuala Lumpur, Malaysia

\section{*Corresponding author:}

Dr. Joo Shun Tan

Tel: +6046536376

Fax: +6046536375

E-mail address: jooshun@usm.my

Running title: Recovery of a biological product 


\section{ABSTRACT}

23 Background: Current advances in biotechnology have been looked at as alternative approaches

24 towards the limited product recovery due to time- and cost-consuming drawbacks on the conventional purification methods. This study aimed to purify bovine serum albumin (BSA) as an exemplary target product using an aqueous impregnated resin system (AIRS). This method implies the concept of hydrophobicity of polymer that impregnated into the resins and driven by electrostatic attractions and hydrophilicity of aqueous salt solution to extract the target product.

Methods: The extraction behaviors of impregnation in terms of stability and adsorption kinetics via protein-aqueous polymer impregnated resin were studied. Impregnation stability was determined by the leaching factor of polyethylene glycol (PEG). The major factors such as PEG molecular weights and concentration, $\mathrm{pH}$ of aqueous salt solution, extraction methods (sonication and agitation) and types of adsorbent material and concentration of aqueous salt phase influencing on partitioning of biomolecule were also investigated.

Results: For impregnation stability, the leaching factor for Amberlite XAD4 did not exceed 1\%. The scanning electron microscopy (SEM) image analysis of Amberlite XAD4 attributes the structural changes with impregnation of resins. For adsorption kinetics, Freundlich adsorption isotherm with the highest $\mathrm{R}^{2}$ value $(0.95)$ gives an indication of favorable adsorption process. Performance of AIRS impregnated with 40\% (w/w) of PEG 2000 was found better than aqueoustwo phase system (ATPS) by yielding the highest recovery of BSA (53.72\%). The outcomes of this study propound the scope for the application of AIRS in purification of biomolecules.

Keywords: aqueous impregnated resin system; bovine serum albumin; impregnation stability; adsorption kinetics; polyethylene glycol 


\section{INTRODUCTION}

45 Biological products such as proteins, nucleic acids, microorganisms, animals and plant cells have

46 been widely used in food, pharmaceutical and other industries. Since the upstream processing of

47 these biological products is developing extensively, the downstream processing always leads to

48 the production bottleneck. There are four stages in the downstream processing of biomolecules

49 such as recovery, isolation, purification and polishing (Raja, Selvaraj et al. 2011). Researchers

50 have developed numerous purification strategies in order to obtain high yield of products.

51 However, the production costs for biological products can be up to 80\% (Rosa, PAJ et al. 2011).

52 Aqueous two-phase system (ATPS), which implies the concept of hydrophobicity and ionic

53 charge in polymer and salt phases has been studied for primary recovery of biomolecules.

54 However, long settling times in ATPS could be overcome by centrifugation, which consumes

55 high energy and is considered as the drawback of this method (Iqbal, Mujahid et al. 2016). This

56 strictly limits the development of a biomanufacturing process, especially in purification of

57 valuable bioproducts. This drawback could be prevailed by a combination of ATPS with 58 impregnated resin principle.

59 In AIRS, the aqueous polymer phase is impregnated into the solid materials while the 60 aqueous salt phase represents the surrounding bulk phase. When the polymer impregnated solid materials are suspended in the aqueous salt phase, it creates the mass transfer between the two

62 phases (Tan, Joo Shun et al. 2018). The liquid extractant is retained within the pores of solid materials by capillary forces, which the extractant loss could be minimized compared to conventional liquid-liquid extraction. The extraction mechanism comprises of the diffusion of the solute from the surrounding aqueous bulk phase into the immobilized extractant phase. 
67 takes place during which extractant and solute form a complex extractant-solute. The

68 complexation shifts the extraction equilibrium further towards the immobilized extractant phase. This method implies the concept of hydrophobicity of polymer that being impregnated into solid materials and the hydrophilicity of aqueous salt solution to extract biomolecule. Although this method has been applied in different proteins such as $\beta$-mannanase, esterase and lipase, the systemic and detailed information on this extraction behavior such as impregnation stability and adsorption kinetics have not been well-studied (Abdul Aziz, Nur Fazrin Husna et al. 2018; Grilo, António Lima et al. 2016; Tan, Joo Shun et al. 2020; Tan, Joo Shun et al. 2018).

The aim of this study is to evaluate the extraction behaviors of aqueous polyethylene glycol (PEG) impregnated resin system in terms of impregnation stability and recovery via protein impregnated resin interactions on BSA as exemplary target product. Furthermore, the influencing factors such as molecular weight and concentration of PEG, and $\mathrm{pH}$ and concentration of aqueous salt phase on bovine serum albumin (BSA) partitioning behavior were examined. A comparison between aqueous PEG impregnated resin system and ATPS was evaluated. The information from the study will be used to validate the competency of the system in purification of biomolecules.

\section{MATERIALS AND METHODS}

\section{Schematic overview of the experiment}

The overall experimental process is presented in Figure 1. The processes included the dry impregnation of PEG on the resins, extraction with aqueous salt phase (sodium citrate and 4\% $\mathrm{NaCl}$ ) and back-extraction prior to the analysis such as impregnation stability, adsorption kinetics, extraction behaviors and comparison with ATPS and resins adsorption. 
90

91

92

93

94

95

96

97

98

99

100

101

102

103

104

105

106

107

108

109

110

111

112

\section{Chemicals and Reagents}

PEG with different average molecular weights of $2000 \mathrm{~g} / \mathrm{mol}$ (25322-68-3), $4000 \mathrm{~g} / \mathrm{mol}$ (2532268-3), $6000 \mathrm{~g} / \mathrm{mol}$ (25322-68-3) and $8000 \mathrm{~g} / \mathrm{mol}$ (25322-68-3) were purchased from Milipore, Merck (Darmstadt, Germany). Potassium citrate ( $\geqslant 99.0 \%, 6100-05-6)$, sodium chloride $(\geqslant 99.0 \%, 7647-14-5)$, BSA $(>96 \%, 9048-46-8)$ and Amberlite XAD4 (20-60 mesh, 37380-420) were sourced from Sigma Aldrich (St. Louis, MO). The porous VitraPor glass pellets with two different particle sizes of $4.0 \mathrm{~mm} 8.00 \mathrm{~mm}$ were supplied from ROBU Glassfilter-Gerate $\mathrm{GmbH}$ (Hattert, Germany). PageBlue protein staining solution and protein loading buffer were all from Fermentas (St. Leon-Rot, Germany).

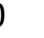

\section{Impregnation stability of PEG on porous solids}

In order to determine the impregnation stability on the porous solids, an experiment on the impregnation stability was performed quantitatively. The experiments were started by preparing different concentrations of PEG $(10 \% \mathrm{w} / \mathrm{w}, 20 \% \mathrm{w} / \mathrm{w}, 30 \% \mathrm{w} / \mathrm{w}$ and $40 \% \mathrm{w} / \mathrm{w})$ with different molecular weights of $2000 \mathrm{~g} / \mathrm{mol}, 4000 \mathrm{~g} / \mathrm{mol}, 6000 \mathrm{~g} / \mathrm{mol}$ and $8000 \mathrm{~g} / \mathrm{mol}$. In order to determine the percentage of leached polymer phase, the polymer phase was dyed with $1.0 \mathrm{mg} / \mathrm{mL}$ of Patent blue V. The effects of pore size, particle size and materials on the impregnation stability were evaluated. Three types of solid materials such as VitraPor glass beads with diameter size $4.0 \mathrm{~mm}$ and $8.0 \mathrm{~mm}$ and Amberlite XAD4 (diameter size distribution of $0.25-0.84 \mathrm{~mm}$ ) were used to impregnate the PEGs via dry impregnation method (Van Nguyen, Nghiem et al. 2013). VitraPor glass beads are inert porous glass beads with defined pore sizes of approximately $60 \mu \mathrm{m}$ while Amberlite XAD4 is polymeric adsorbent with a pore size of approximately $0.005 \mu \mathrm{m}$. Both 
113 VitraPor glass beads and Amberlite XAD4 have structural rigidity, good mechanical stability and

114 zero or minimal expansion in organic solvents. These PEG impregnated resins were suspended

115 into $20 \%(\mathrm{w} / \mathrm{w})$ of sodium citrate solution and agitated in incubator shaker (Infors HT,

116 Switzerland) at $200 \mathrm{rpm}, 30^{\circ} \mathrm{C}$ for $180 \mathrm{~min}$. The contact time was fixed at $180 \mathrm{~min}$ based on our

117 preliminary study, in which the leaching percentage was stable after $30 \mathrm{~min}$. For the quantitative

118 evaluation of leaching, the leaching percentage from each sample solution at 30 min interval for

119180 min was determined by measuring the absorbance of Patent blue V-dyed PEG at $620 \mathrm{~nm}$

120 using microplate reader (Halo MPR-96 Visible Microplate Reader, Dynamica). The leaching

121 percentage of PEG were calculated using Eq(1):

122 Leaching percentage $(\%)=\frac{\text { Absorbance } 620 \mathrm{~nm} \text { of leached PEG }}{\text { Absorbance } 620 \mathrm{~nm} \text { of impregnated PEG }} \times 100$

\section{Experimental design}

124 Two different aqueous solutions, PEG and sodium citrate were prepared as described by Tan et 125 al., (2018). Dry impregnation method was used to impregnate PEGs to resins. Briefly, the PEG solution was added drop by drop into the resins until all the resins were fully impregnated with

127 PEG. A $2 \mathrm{~g}$ of impregnated resins was added into the aqueous salt solution containing $1 \%$ (w/w) of BSA and incubated at $30^{\circ} \mathrm{C}$ for 30 min with agitation speed of $150 \mathrm{rpm}$ to enhance the mass transfer rate. For back extraction, the impregnated porous solids containing the BSA were filtered out from the citrate solution containing $4 \%$ of $\mathrm{NaCl}$ using a sieve (100 mesh size). The excess salt solutions on the solid's surface were dried and suspended into aqueous citrate solution in the absence of $\mathrm{NaCl}$ for desorption process. $\mathrm{BSA}$ is one of the major serum proteins; it plays an important role as a result of its functional and nutritional properties which have

134 bioactive peptides. Its low cost and wide availability compared to other proteins, its structure and 
135 functional similarity to human serum albumin enable its various biotechnological applications.

136 Based on these aspects, BSA has been extensively applied as the model protein in various

137 extraction and purification studies. For instance, BSA has been used as a model in the separating

138 process using hydroxyapatite and active babassu coal (Pereira, Matheus M et al. 2015; Ribeiro

139 Alves, Márcia Regina et al. 2016).

140

141

142

143

144

145

146

147

148

149

150

151

152

153

154

155

156

157 Statistical analysis

\section{Determination of bovine serum albumin separation performance using AIRS}

To investigate the protein separation performance using AIRS, the effects of the influencing factors on partitioning behaviors were studied. The factors consisted of the PEG molecular weights $(2000 \mathrm{~g} / \mathrm{mol}, 4000 \mathrm{~g} / \mathrm{mol}, 6000 \mathrm{~g} / \mathrm{mol})$, concentration of PEG (5\% w/w, 10\% w/w, 15\% $\mathrm{w} / \mathrm{w}$ and $20 \% \mathrm{w} / \mathrm{w})$, and $8000 \mathrm{~g} / \mathrm{mol}), \mathrm{pH}$ of sodium citrate $(5.0,6.0,7.0$, and 8.0$)$, method of extraction viz. sonication and agitation, type of solid materials (VitraPor glass beads $4.0 \mathrm{~mm}$ diameter, VitraPor glass beads $8.0 \mathrm{~mm}$ and Amberlite XAD4), and salt concentration $(10 \% \mathrm{w} / \mathrm{w}$, $20 \% \mathrm{w} / \mathrm{w}$ and $30 \% \mathrm{w} / \mathrm{w})$. One-factor-at-a-time was used while the other factors were fixed. The recovery yield of the protein was calculated using Equation (2) where $C_{o}$ and $C_{t}$ referred to the initial concentration of the protein in the aqueous citrate phase and concentration of the protein in the aqueous citrate phase after back-extraction.

$$
\text { Recovery yield }(\%)=\frac{C o-C t}{C o} \times 100 \%
$$

Determination of Protein Content. Total protein concentration was determined using a BioRad protein assay kit with albumin as a standard protein (Abdul Aziz, Nur Fazrin Husna et al. 2020). A total of $10 \mu \mathrm{L}$ of the sample was added to $200 \mu \mathrm{L}$ of Bradford reagent in a microtiter plate and incubated at $37^{\circ} \mathrm{C}$ for $15 \mathrm{~min}$. Absorbance was measured at $595 \mathrm{~nm}$ using a microplate reader (Halo MPR-96 Visible Microplate Reader, Dynamica). 
158 All the data represent the mean of three independent experiments. The errors during the

159 measurement were indicated by standard deviations. The statistical analysis and regression 160 coefficient $\left(\mathrm{R}^{2}\right)$ values of the linear form of Langmuir isotherm and Freundlich isotherm models

161 were determined using statistical functions of Microsoft Excel 2010.

\section{RESULTS}

\section{Impregnation stability}

165 Results from the leaching percentage of different PEG molecular weights and concentration on 166 different types of resins are presented in Table 1. The leaching factor for Amberlite XAD4 did not exceed 1\%. The leaching factors for VitraPor glass beads with diameter sizes of $8.0 \mathrm{~mm}$ and $4.0 \mathrm{~mm}$ were higher as compared to XAD4. The pore size of Amberlite XAD4 $(0.005 \mu \mathrm{m})$ is much smaller as compared to VitraPor glass beads $(60 \mu \mathrm{m})$. The smaller pore size of the solid materials had higher impregnation stability. The PEG leaching profile depends on the PEG molecular weight and concentration, and a slower release rate is observed for the higher molecular weight and concentration. When the PEG 2000 was used, $23.74 \%$ to $20.19 \%$ of the

173 PEG at concentrations of $10 \%(\mathrm{w} / \mathrm{w})$ in the impregnation had been leached out from the VitraPor glass beads $4.0 \mathrm{~mm}$ and $8.0 \mathrm{~mm}$, respectively. The leaching percentage decreased to $7.36 \%$ when the concentration of PEG 2000 increased to 40\% (w/w). Similarly, PEG 4000 and PEG 6000 in both VitraPor glass beads had higher leaching percentages at lower concentrations (10\% and $17720 \%$ ). The leaching percentage successfully reduced to less than $5 \%$ when the concentrations increased to $30 \%$ and $40 \%$, respectively. Scanning electron micrographs (SEM) of Amberlite XAD4 before and after impregnation with PEG 4000 are presented in Figure 2. Smooth surface 
180 of Amberlite XAD4 in Figure 2(B) indicated that the PEG had been impregnated into the resins,

181 by filling the porous of the resins.

\section{Adsorption kinetics of BSA into resins}

183 Comparison of different coefficients from Langmuir and Freundlich adsorption isotherm of BSA 184 on PEG impregnated resins are presented in Table 2. Langmuir isotherm yielded a negative 185 value of maximum BSA uptake by PEG impregnated resin, $-3.87 \mathrm{mg} / \mathrm{g}$ while the Freundlich 186 isotherm provided adsorption capacity, $\mathrm{K}_{\mathrm{f}}$ of $6.28 \mathrm{mg} / \mathrm{g}$. Freundlich adsorption isotherm has the 187 highest $\mathrm{R}^{2}$ value (0.95) which is near to 1. For Freundlich model, intensity of adsorption (n) 188 gives an indication of favorable adsorption process. This indicates the adsorption of BSA on PEG impregnated resins followed the Freundlich isotherm.

Effect of molecular weight and concentration of PEG, pH and concentration of sodium citrate on the BSA recovery yield

192 193

Effects of the PEG molecular weight and concentration on the BSA recovery yield are presented in Figure 3A. Four different PEG molecular weights $(2000 \mathrm{~g} / \mathrm{mol}, 4000 \mathrm{~g} / \mathrm{mol}, 6000 \mathrm{~g} / \mathrm{mol}$ and $8000 \mathrm{~g} / \mathrm{mol})$ were used, each at different concentrations $(10 \% \mathrm{w} / \mathrm{w}, 20 \% \mathrm{w} / \mathrm{w}, 30 \% \mathrm{w} / \mathrm{w}$ and $40 \% \mathrm{w} / \mathrm{w})$. The recovery of BSA increased when using lower molecular weights of PEG. PEG 2000 and PEG 4000 showed similar trend where the recovery of BSA increased as the concentration of PEG increased. In contrast, a decrease in depleted protein could be observed with higher molecular weights of PEG (6000 and 8000).

In order to determine the optimum $\mathrm{pH}$ for the maximum depletion of $\mathrm{BSA}$, the $\mathrm{pH}$ of the sodium citrate solution was varied from $\mathrm{pH} \mathrm{5,6,7}$ and 8 and the results are presented in Figure 3B. According to our experiment, increasing the $\mathrm{pH}$ of sodium citrate solution from 5 to 7 increased the BSA yield. The yield of recovered BSA for $\mathrm{pH} 5,6$ and 7 are $30.98 \%, 34.97 \%$ and 
$20351.08 \%$ respectively. However, further increase in the $\mathrm{pH}$ to $\mathrm{pH} 8$ reduced the BSA yield

204 (41.39\%). From this experiment, pH 7.0 is selected to be used in subsequent experiment since it 205 is the optimum $\mathrm{pH}$ for the BSA extraction.

206 The sodium citrate concentration up to $30 \%(\mathrm{w} / \mathrm{w})$ was tested to determine the effect of 207 salt concentration on the recovery of BSA in AIRS and the results are presented in Figure 3C. 208 The recovery of BSA was slightly different at different concentration of sodium citrate. From 209 this experiment, $10 \%(\mathrm{w} / \mathrm{w})$ of sodium citrate concentration shows highest depletion of BSA $210(50.55 \%)$.

211 Comparisons between AIRS, ATPS and adsorption method on BSA partitioning 212 experiment

213 Comparison between BSA recovery yield using three different types of partitioning experiment 214 (AIRS, ATPS and adsorption) are presented in Figure 4. ATPS was carried out using 40\% (w/w) 215 of PEG 2000 and $10 \%(\mathrm{w} / \mathrm{w})$ of sodium citrate like AIRS for comparison. AIRS yielded the 216 highest recovery of BSA (53.72\%), followed by BSA adsorbed by Amberlite XAD4 without 217 impregnated PEG (46.38\%). ATPS had the lowest BSA recovery yield (41.80\%) among all the 218 partitioning experiments. From this experiment, it was proven that by combining ATPS and 219 adsorption method, the BSA recovery yield could be enhanced.

\section{DISCUSSION}

221 The impregnation stability of different types of solid materials with different molecular weight of 222 PEG was determined prior to BSA partitioning experiment (Refer to Table 1). This is to ensure 223 that the PEG is stably impregnated in the resins, allowing the BSA to be extracted without any 224 leaching of PEG. This is crucial since leaching of PEG into the salt solution restrains the BSA 225 from adsorbing to the impregnated resins. The leaching factor for Amberlite XAD4 did not 
226 exceed 1\% which indicated the impregnation using Amberlite XAD4 was stable for the BSA

227 partitioning experiment. Amberlite XAD4 is hydrophobic polyaromatic and used to adsorb small

228 hydrophobic compounds, like PEG (Li, Aimin et al. 2001). This chemical structure makes the

229 PEG strongly bound into the resins, resulted in low leaching percentage. Additionally, Amberlite

230 XAD4 represents a solid with smaller particle size distribution and smaller pore size distribution

231 than VitraPor glass pellets. An influence of the pore size on leaching could be expected because

232 leaching is induced at the pores outlet at the interface of the two aqueous phases. A decrease of

233 the pore size reduces the interface and thus, potentially decreases leaching. On the other hand,

234 smaller particle size leads to a larger interface between the phases and shorter distances for

235 intraparticular mass transport but the polymeric nature of Amberlite XAD4 has overcome this

236 limitation and the small particles size offers the possibility of faster partitioning of protein during

237 purification (Kaplanow, I et al. 2018).

The results (Refer to Table 1) showed that the PEG leaching was dependent on the

molecular weight and concentration of PEG, with leaching percentage decreasing from low to

high molecular weight and concentration and then remained below 5\% of leaching percentage

for the highest molecular weight and concentration of PEG. PEG concentration at $40 \%(\mathrm{w} / \mathrm{w})$ is

near to saturation. This implies the existence of a maximum leaching factor, which would make

243 it possible to fine-tune the impregnation to fit the application by selecting the optimal molecular

244 weight and concentration of PEG. At lower concentration of PEG, a higher rate of diffusion

245 could be observed than larger molecules as large volumes of the water has been enclosed

246 together with the soluble PEG in the insoluble impregnated resins and thereby always gets

247 exposed to water and prone to be dissolved in the surrounding bulk solution (Marucci,

248 Mariagrazia et al. 2011). Another explanation is the differences in molecular weight of the 
249 polymers. PEG 6000 and PEG 8000 are much heavier than PEG 2000 and PEG 4000, therefore

250 exhibits a much lower rate of diffusion. The increased molecular weight also affects the

251 dissolution properties, a longer polymer chain is less prone to be dissolved than a shorter one

252 (Andersson, Helene et al. 2016). The smooth surface of Amberlite XAD4 indicated that the PEG

253 had been impregnated into the resins, by filling the porous of the resins (Refer to Figure 2).

254 In the study of adsorption kinetics, pseudo-first-order kinetic model or pseudo-second-

255 order kinetic model are used to investigate the mechanism of solute adsorption onto extractant

256 while adsorption isotherms such as Langmuir and Freundlich isotherms are used to describe the

257 experimental sorption data for evaluating the adsorption equilibrium (Murcia-Salvador, Ainoa et

258 al. 2019). To evaluate the adsorption capacity and favourable adsorption process, adsorption

259 equilibrium is best fit for our study. The efficiency of adsorption of BSA from aqueous media

260 using a newly developed PEG impregnated resin suggested that a contact time of 30 min sufficed

261 to reach the saturation point and the adsorption of BSA was slowed down after that. Freundlich

262 adsorption isotherm has the highest $\mathrm{R}^{2}$ value (0.95) which is near to 1 (Refer to Table 2). For

263 Freundlich model, intensity of adsorption (n) gives an indication of favorable adsorption process.

264 Values of $\mathrm{n}$ greater than 1 represent favorable adsorption condition. This indicates the adsorption

265 followed the Freundlich isotherm more closely than it did the Langmuir isotherm.

266 Since polymer is one of the major components in AIRS, it is crucial to determine the

267 effect of the PEG molecular weight and concentration on the BSA recovery yield (Refer to

268 Figure 3A). The recovery of BSA increased as the concentration of PEG increased. This is

269 probably due to higher molecular weight of PEG which has higher excluded effect, thus less

270 BSA molecules are being extracted into the PEG impregnated resins. This phenomenon results in

271 the lower depleted BSA (Nascimento, Kelany S et al. 2010). On the other hand, higher 
272 concentration of PEG show higher depleted protein. This might be due to higher concentration of

273 PEG which had higher impregnation stability, and caused more BSA adsorbed into the PEG.

274 This phenomenon is in line with the findings of Raja et al. (2011) where higher concentration of

275 polymer increased the differences in density, refractive index and viscosity between the polymer

276 and aqueous salt phase. Higher density difference would prevent the polymer to be leached out

277 from the solid materials, enables it to bind more protein molecule. Unlike tunable aqueous

278 polymer phase impregnated resins (TAPPIR) technology presented by Bernhard Burghoff (2013)

279 where conventional aqueous two-phase extraction (ATPE) was relied, AIRS could impregnate 280 maximum $40 \%(\mathrm{w} / \mathrm{w})$ of impregnated polymer.

As the protein extraction in AIRS is highly affected by the charges of the protein, $\mathrm{pH}$ plays an important role in increasing the yield of the depleted protein (Refer to Figure 3B). As the $\mathrm{pH}$ of the sodium citrate solution is varied, the charge of the solute changes (Saravanan, Settu et al. 2008). In order to determine the optimum $\mathrm{pH}$ for the maximum depletion of BSA, the $\mathrm{pH}$ of the sodium citrate solution was varied from $\mathrm{pH} \mathrm{5,6,7}$ and 8. According to our experiment, increasing the $\mathrm{pH}$ of sodium citrate solution from 5 to 7 increased the BSA yield. However further increase in the $\mathrm{pH}$ to $\mathrm{pH} 8$ reduced the BSA yield. This is mainly because, the BSA becomes negatively charged as the $\mathrm{pH}$ of sodium citrate solution is above the isoelectric point of BSA ( 5.0), the point at which the BSA has a net charge of zero (Phan, Hanh TM et al. 2015). BSA was repelled by the negatively charged sodium citrate solution, resulted in the increase in adsorption of BSA and the recovery yield. In contrast, the decreasing of BSA recovery yield at pH 8 could be explained as the BSA molecular structure may have changes, causing it to unable to be partitioned into the solid material containing PEG at higher $\mathrm{pH}$ solution (Silva, Daniel

Pereira da et al. 2002). The recovery of BSA was varied at different concentrations of sodium 
295 citrate. However, choosing the optimum salt concentration is important as it determines the

296 maximum crude loading which it can accommodate.

A comparison on BSA recovery yield obtained using three different types of partitioning experiment (AIRS, ATPS and adsorption) in Figure 4 showed that AIRS yielded the highest recovery of BSA (53.72\%), followed by BSA adsorbed by Amberlite XAD4 without impregnated PEG (46.38\%). ATPS had the lowest BSA recovery yield (41.80\%) among all the adsorption method, the BSA recovery yield could be enhanced.

\section{CONCLUSION}

304

305

306

307

308

It could be concluded from this study that AIRS promoted a novel approach in extraction and purification of biological product. This study showed that stable impregnation could be achieved with polymeric resins and approximately $50 \%$ of BSA could be extracted using this method. This method has advantages as compare to ATPS where in this method, the stage of phase forming is omitted and only relies on the hydrophobicity of polymer and hydrophilicity and electrostatic charge of salt. It also provides wider range of polymer concentration and salt concentration. Despite the fact that this method has many advantages, the usage of resins in this experiment increase the total production cost. However, the reusability of the impregnated resin overcome this problem.

\section{ACKNOWLEDGEMENTS}

Authors acknowledge the financial supports received by Ministry of Higher Education (MOHE), Malaysia under Fundamental Research Grant Scheme (203/PTENKIND/6711624) and Prototype Research Grant Scheme (203/PTENKIND/6740048).

\section{ADDITIONAL INFORMATION AND DECLARATIONS}




\section{Funding}

319 A financial support was received from Ministry of Higher Education (MOHE), Malaysia under

320 Prototype Research Grant Scheme (203/PTENKIND/6740048).

\section{Competing interests}

322 The authors declare that they have no competing interests.

\section{Author Contributions}

324 Conceptualization, Joo Shun Tan and Sahar Abbasiliasi; Methodology, Nur Fazrin Husna \& 325 Mazni Abu Zarin; Supervision, Joo Shun Tan, Sahar Abbasiliasi and Hui-Suan Ng; Writing326 original draft, Nur Fazrin Husna \& Mazni Abu Zarin; Writing-review and editing, Joo Shun 327 Tan and Sahar Abbasiliasi. All authors have read and agreed to the published version of the 328 manuscript.

329 Data availability

330 N/A

331 Supplemental Information

332 N/A 


\section{REFERENCES}

Abdul Aziz NFH, Abbasiliasi S, Ariff AB, Ng HS, Lan JC-W, Ahmad R, and Tan JS. 2018. Optimization of recovery of esterase from Serratia marcescens using combination of the solvent impregnated resin and aqueous two-phase extraction techniques. Separation Science and Technology 53:2952-2960.

Abdul Aziz NFH, Abbasiliasi S, Ng ZJ, Abu Zarin M, Oslan SN, Tan JS, and Ariff AB. 2020. Recovery of a Bacteriocin-Like Inhibitory Substance from Lactobacillus bulgaricus FTDC 1211 Using Polyethylene-Glycol Impregnated Amberlite XAD-4 Resins System. Molecules 25:5332.

Andersson H, Häbel H, Olsson A, Sandhagen S, von Corswant C, Hjärtstam J, Persson M, Stading M, and Larsson A. 2016. The influence of the molecular weight of the watersoluble polymer on phase-separated films for controlled release. International journal of pharmaceutics 511:223-235.

Burghoff B. 2013. Tunable aqueous polymer phase impregnated resins: A combination of the extractant impregnated resin principle and aqueous two-phase systems. Separation Science and Technology 48:2159-2163.

Grilo AL, Raquel Aires-Barros M, and Azevedo AM. 2016. Partitioning in aqueous two-phase systems: fundamentals, applications and trends. Separation \& Purification Reviews 45:68-80.

Iqbal M, Tao Y, Xie S, Zhu Y, Chen D, Wang X, Huang L, Peng D, Sattar A, and Shabbir MAB. 2016. Aqueous two-phase system (ATPS): an overview and advances in its applications. Biological procedures online 18:18.

Kaplanow I, Schmalenberg M, Borgmann I, Schembecker G, and Merz J. 2018. Tunable aqueous

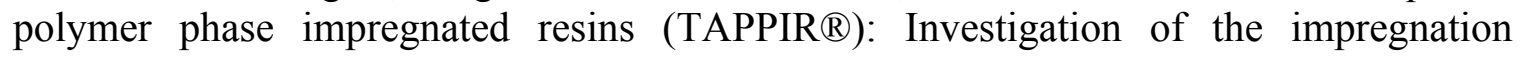
stability. Separation and Purification Technology 190:1-8.

Li A, Zhang Q, Chen J, Fei Z, Long C, and Li W. 2001. Adsorption of phenolic compounds on Amberlite XAD-4 and its acetylated derivative MX-4. Reactive and Functional Polymers 49:225-233.

Marucci M, Ragnarsson G, von Corswant C, Welinder A, Jarke A, Iselau F, and Axelsson A. 2011. Polymer leaching from film coating: Effects on the coating transport properties. International journal of pharmaceutics 411:43-48.

Murcia-Salvador A, Pellicer JA, Fortea MI, Gómez-López VM, Rodríguez-López MI, NúñezDelicado E, and Gabaldón JA. 2019. Adsorption of Direct Blue 78 using chitosan and cyclodextrins as adsorbents. Polymers 11:1003.

Nascimento KS, Azevedo A, Cavada B, and Aires-Barros M. 2010. Partitioning of Canavalia brasiliensis lectin in polyethylene glycol-sodium citrate aqueous two-phase systems. Separation Science and Technology 45:2180-2186. 
370

371

372

373

374

375

376

377

378

379

380

381

382

383

384

385

386

387

388

389

390

391

392

393

394

395

396

397

398

399

400

401

402

403

404
Pereira MM, Pedro SN, Quental MV, Lima ÁS, Coutinho JA, and Freire MG. 2015. Enhanced extraction of bovine serum albumin with aqueous biphasic systems of phosphonium-and ammonium-based ionic liquids. Journal of biotechnology 206:17-25.

Phan HT, Bartelt-Hunt S, Rodenhausen KB, Schubert M, and Bartz JC. 2015. Investigation of bovine serum albumin (BSA) attachment onto self-assembled monolayers (SAMs) using combinatorial quartz crystal microbalance with dissipation (QCM-D) and spectroscopic ellipsometry (SE). PloS one 10:e0141282.

Raja S, Murty VR, Thivaharan V, Rajasekar V, and Ramesh V. 2011. Aqueous two phase systems for the recovery of biomolecules-a review. Science and Technology 1:7-16.

Ribeiro Alves MR, Zuñiga ADG, Sousa RdCS, and Zacchi Scolforo C. 2016. The process of separating bovine serum albumin using hydroxyapatite and active babassu coal (Orbignya Martiana). The Scientific World Journal 2016.

Rosa P, Azevedo A, Sommerfeld S, Bäcker W, and Aires-Barros M. 2011. Aqueous two-phase extraction as a platform in the biomanufacturing industry: economical and environmental sustainability. Biotechnology advances 29:559-567.

Saravanan S, Rao JR, Nair BU, and Ramasami T. 2008. Aqueous two-phase poly (ethylene glycol)-poly (acrylic acid) system for protein partitioning: Influence of molecular weight, pH and temperature. Process biochemistry 43:905-911.

Silva DPd, Pontes MZR, Souza MAd, Vitolo M, and Pessoa-Junior A. 2002. Infleunce of pH on the partition of glucose-6-phosphate dehydrogenase and hexokinase in aqueous twophase system. Brazilian Journal of Microbiology 33:196-201.

Tan JS, Abbasiliasi S, Ariff A, Murugan P, Hafizi MAB, and Ng HS. 2020. Polymer impregnation in porous glass beads to induce bioseparation of $\beta$-mannanase from fermentation broth of Proteus vulgaris. Minerva Biotecnologica 32:43-51.

Tan JS, Abbasiliasi S, Ariff AB, Ng HS, Bakar MHA, and Chow YH. 2018. Extractive purification of recombinant thermostable lipase from fermentation broth of Escherichia coli using an aqueous polyethylene glycol impregnated resin system. 3 Biotech 8:288.

Van Nguyen N, Lee J-c, Jeong J, and Pandey B. 2013. Enhancing the adsorption of chromium (VI) from the acidic chloride media using solvent impregnated resin (SIR). Chemical engineering journal 219:174-182. 
Figure 1

Schematic overview of the experiment 


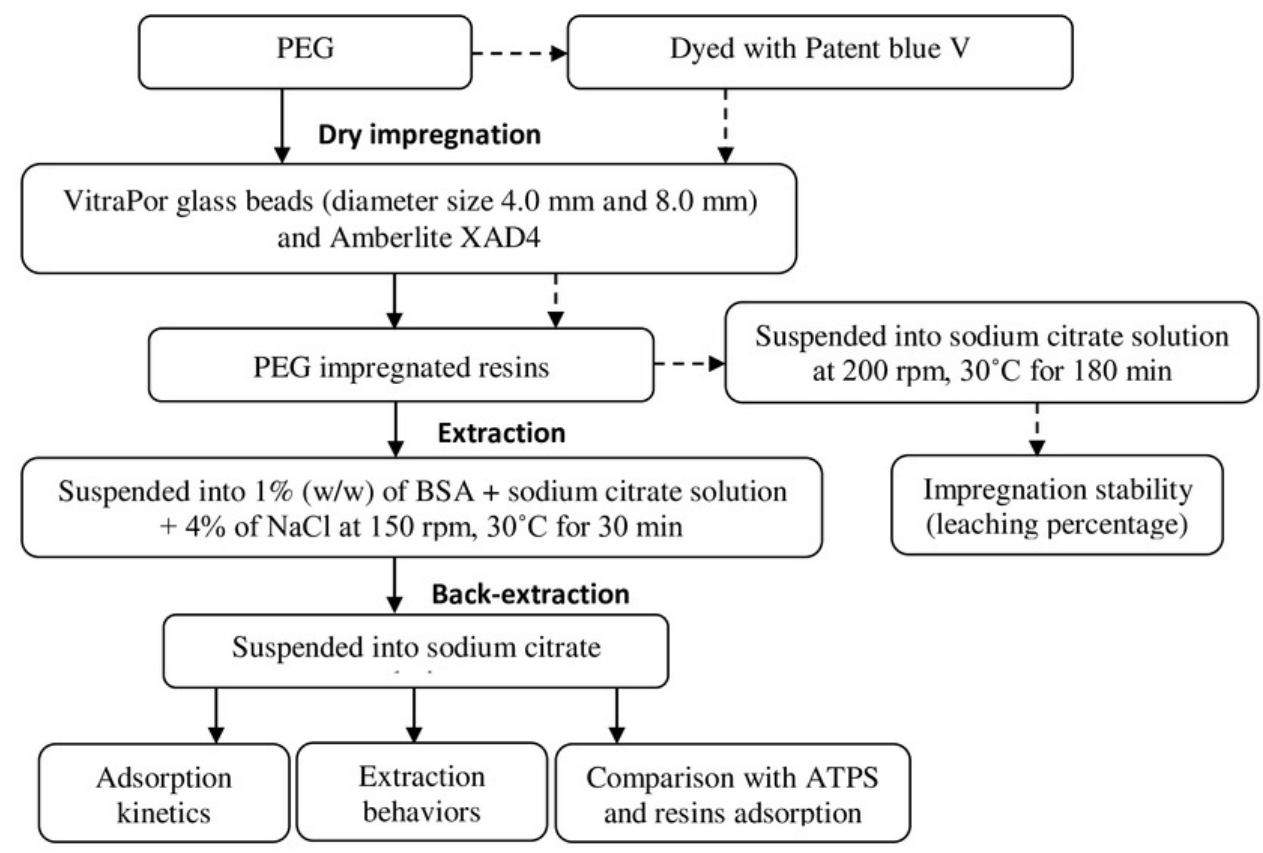


Figure 2

SEM image analysis of Amberlite XAD4 before (A) and after (B) impregnation under 50x magnification. 


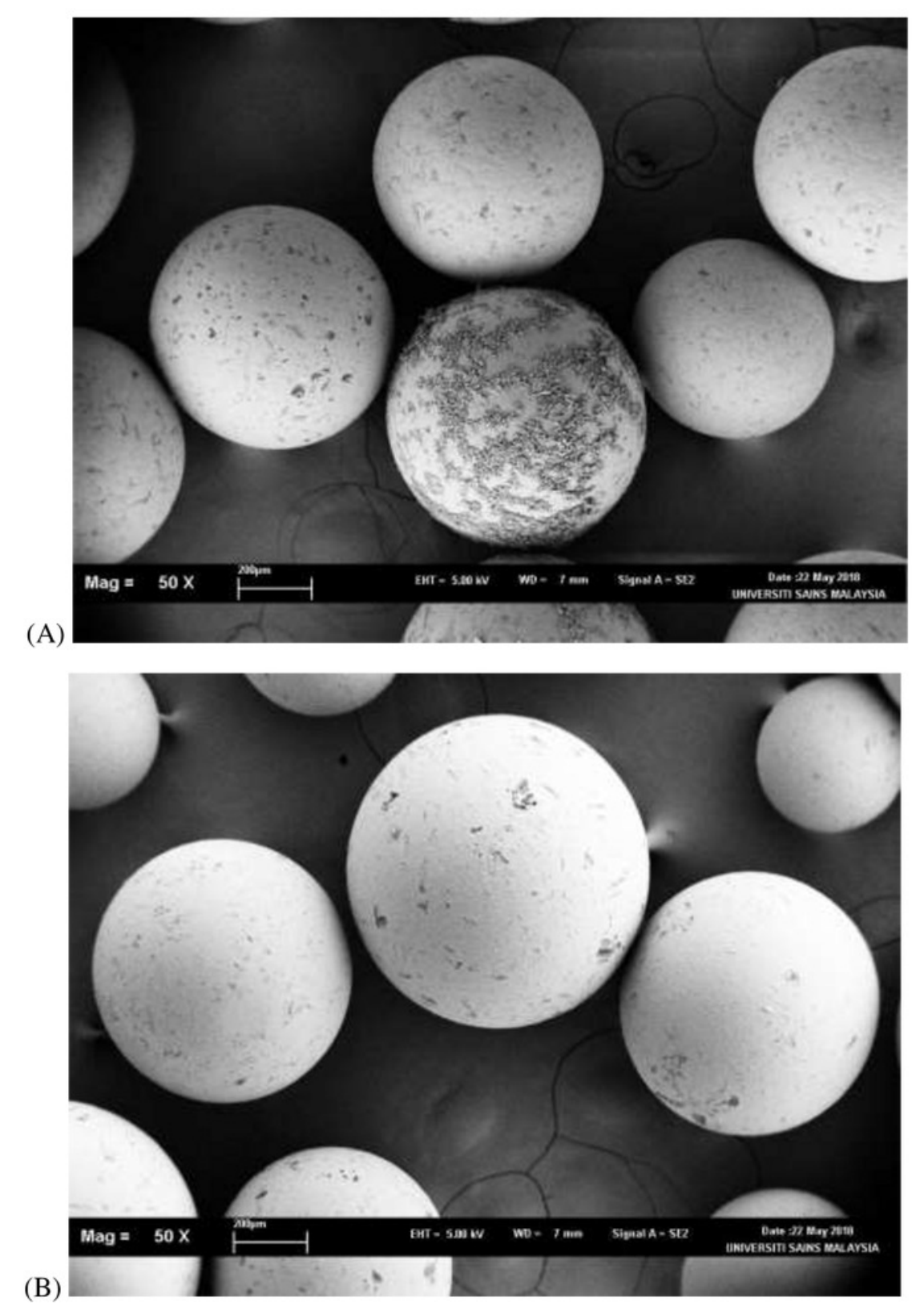


Figure 3

Effect of molecular weight and concentration of PEG (A), pH of sodium citrate (B) and concentration of sodium citrate $(C)$ on BSA partitioning behavior. The results reported as a mean of triplicate reading with an estimated error of $\pm 5 \%$. 


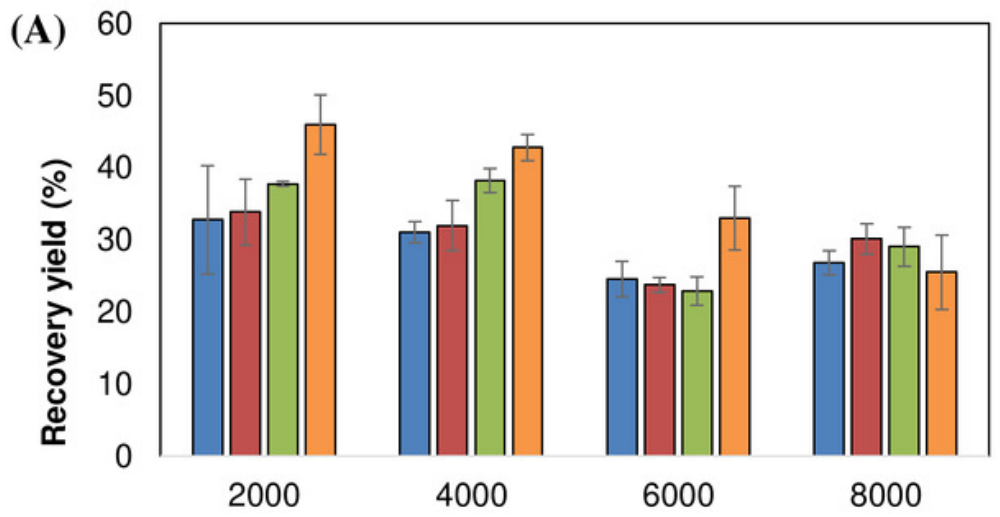

PEG molecular weight and PEG concentration $\square 10 \% \mathrm{w} / \mathrm{w} \quad \square 20 \% \mathrm{w} / \mathrm{w} \quad \square 30 \% \mathrm{w} / \mathrm{w} \backsim 40 \% \mathrm{w} / \mathrm{w}$
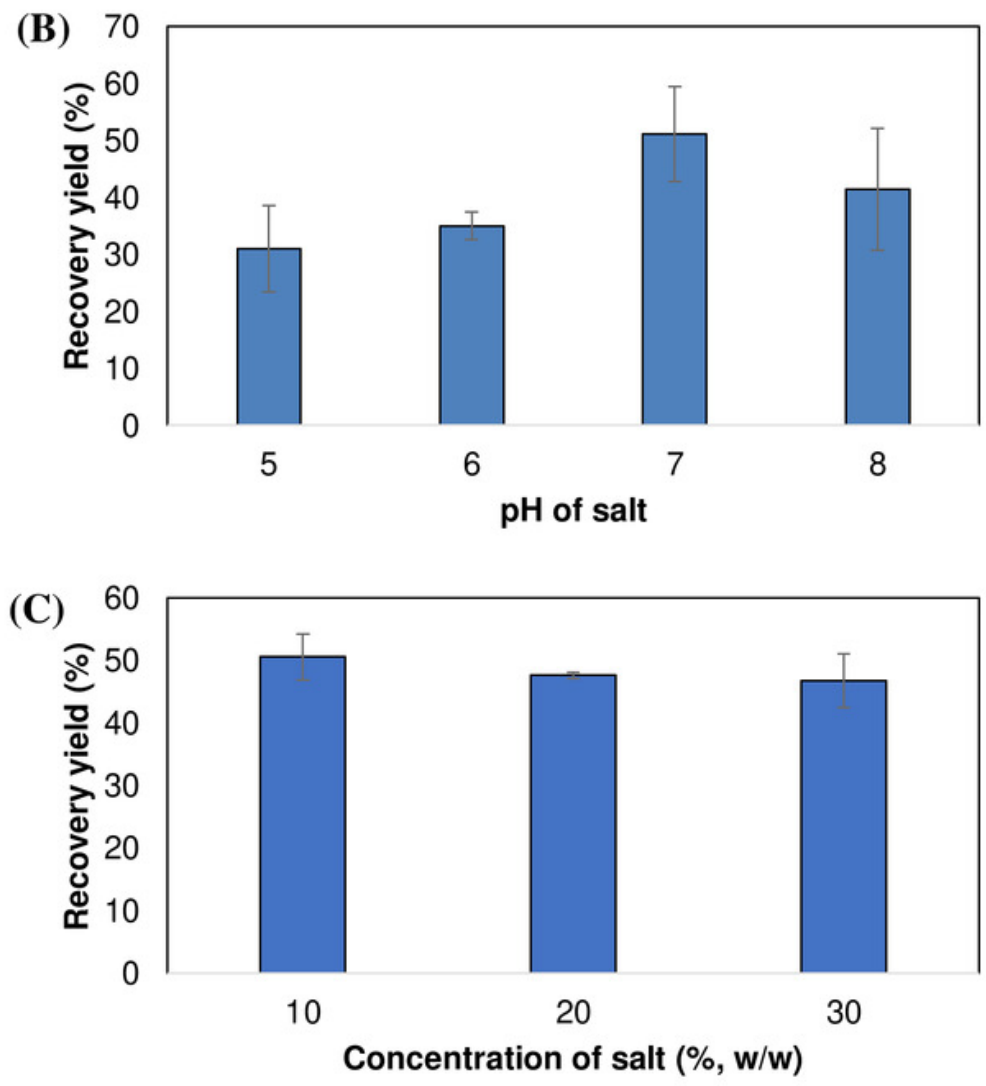
Figure 4

BSA recovery yield obtained using different types of partitioning experiment. The results reported were expressed as a mean of triplicate reading with an estimated error of $\pm 5 \%$. 


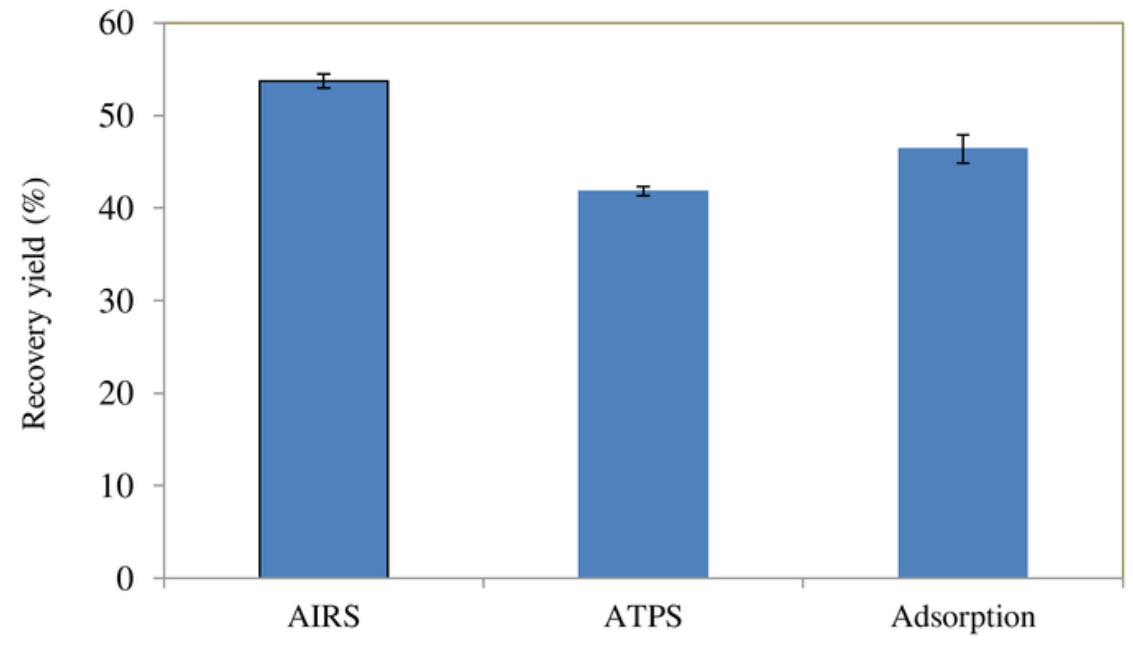


Table $\mathbf{1}$ (on next page)

Leaching percentage of different PEG molecular weight and concentration on different types of resins 
1

Types of solid PEG molecular weight $\quad$ PEG concentration Leaching factor material

$(\mathrm{g} / \mathrm{mol})$

$(\%)$

$(\%)$

\begin{tabular}{|c|c|c|c|}
\hline \multirow[t]{13}{*}{ XAD4 } & 2000 & 10 & $0.55 \pm 0.02$ \\
\hline & & 20 & $0.49 \pm 0.01$ \\
\hline & & 30 & $0.50 \pm 0.06$ \\
\hline & & 40 & $0.54 \pm 0.04$ \\
\hline & 4000 & 10 & $0.40 \pm 0.04$ \\
\hline & & 20 & $0.43 \pm 0.02$ \\
\hline & & 30 & $0.50 \pm 0.07$ \\
\hline & & 40 & $0.53 \pm 0.03$ \\
\hline & 6000 & 10 & $0.43 \pm 0.07$ \\
\hline & & 20 & $0.45 \pm 0.05$ \\
\hline & & 30 & $0.58 \pm 0.01$ \\
\hline & & 40 & $0.57 \pm 0.01$ \\
\hline & 8000 & 10 & $0.49 \pm 0.03$ \\
\hline \multirow{7}{*}{ VitraPor 4.0} & & 20 & $0.58 \pm 0.04$ \\
\hline & & 30 & $0.41 \pm 0.07$ \\
\hline & & 40 & $0.64 \pm 0.07$ \\
\hline & 2000 & 10 & $23.74 \pm 0.89$ \\
\hline & & 20 & $18.74 \pm 1.09$ \\
\hline & & 30 & $10.50 \pm 0.87$ \\
\hline & & 40 & $7.36 \pm 0.05$ \\
\hline
\end{tabular}




\begin{tabular}{|c|c|c|c|}
\hline & 4000 & 10 & $9.02 \pm 0.81$ \\
\hline & & 20 & $5.71 \pm 1.07$ \\
\hline & & 30 & $4.39 \pm 0.73$ \\
\hline & & 40 & $3.22 \pm 0.07$ \\
\hline & 6000 & 10 & $8.31 \pm 0.01$ \\
\hline & & 20 & $6.85 \pm 0.05$ \\
\hline & & 30 & $5.09 \pm 0.04$ \\
\hline & & 40 & $4.06 \pm 0.02$ \\
\hline & 8000 & 10 & $6.67 \pm 0.06$ \\
\hline & & 20 & $4.72 \pm 0.07$ \\
\hline & & 30 & $3.70 \pm 0.07$ \\
\hline & & 40 & $2.65 \pm 0.01$ \\
\hline \multirow[t]{12}{*}{ VitraPor 8.0} & 2000 & 10 & $20.19 \pm 1.08$ \\
\hline & & 20 & $17.88 \pm 1.69$ \\
\hline & & 30 & $9.99 \pm 1.52$ \\
\hline & & 40 & $7.07 \pm 0.95$ \\
\hline & 4000 & 10 & $10.44 \pm 1.19$ \\
\hline & & 20 & $6.44 \pm 0.16$ \\
\hline & & 30 & $5.05 \pm 0.86$ \\
\hline & & 40 & $3.73 \pm 0.07$ \\
\hline & 6000 & 10 & $8.99 \pm 0.43$ \\
\hline & & 20 & $7.49 \pm 1.12$ \\
\hline & & 30 & $5.52 \pm 0.86$ \\
\hline & & 40 & $4.27 \pm 0.96$ \\
\hline
\end{tabular}




\begin{tabular}{lcc}
\hline 8000 & 10 & $7.88 \pm 1.22$ \\
& 20 & $5.05 \pm 0.02$ \\
& 30 & $3.98 \pm 0.09$ \\
& 40 & $3.10 \pm 0.02$ \\
\hline
\end{tabular}

2

3

4

5

6

7 
Table 2 (on next page)

Comparison of different coefficients from Langmuir and Freundlich adsorption isotherm of BSA on PEG impregnated resins. 
1

\begin{tabular}{|c|c|c|c|c|c|}
\hline \multicolumn{3}{|c|}{ Langmuir isotherm } & \multicolumn{3}{|c|}{ Freundlich isotherm } \\
\hline $\begin{array}{c}\text { Maximum } \\
\text { sorbate } \\
\text { uptake, } \\
\text { Q }\end{array}$ & $\begin{array}{l}\text { Coefficient related } \\
\text { to affinity between } \\
\text { adsorbent and } \\
\text { adsorbate, } \\
\text { b }\end{array}$ & $\mathrm{R}^{2}$ & $\begin{array}{c}\text { Adsorption } \\
\text { capacity, } \\
\mathrm{K}_{\mathrm{f}}\end{array}$ & $\begin{array}{l}\text { Adsorption intensity } \\
\text { constant, } \\
\mathrm{n}\end{array}$ & $\mathrm{R}^{2}$ \\
\hline$(\mathrm{mg} / \mathrm{g})$ & $(\mathrm{L} / \mathrm{mg})$ & & $(\mathrm{mg} / \mathrm{g})$ & & \\
\hline-3.87 & -1.40 & 0.76 & 6.28 & 1.46 & 0.95 \\
\hline
\end{tabular}

2 